\title{
Pola Asuh Terhadap Anak Tunarungu dalam Manga Koe No Katachi Karya Ooima Yoshitoki
}

\author{
Nining Vitriani ${ }^{1^{*}}$, I Made Budiana ${ }^{2}$ \\ ${ }^{[123]}$ Program Studi Sastra Jepang Fakultas Ilmu Budaya \\ 1email: nining294@gmail.com], [email: budihybrid@gmail.com] \\ *Corresponding Author
}

\begin{abstract}
Abstrak
Penelitian ini berjudul "Pola Asuh Terhadap Anak Tunarungu dalam Manga Koe No Katachi Karya Ooima Yoshitoki”. Penelitian ini bertujuan untuk mengetahui bentuk pola asuh tokoh ibu, faktor penyebab, serta dampak yang ditimbulkan dari pola asuh terhadap anak tunarungu. Penelitian ini menggunakan metode deskriptif analisis menurut Ratna (2014). Teori yang digunakan dalam penelitian ini adalah teori sosiologi sastra yang dikemukakan oleh Wellek dan Warren (dalam Damono,1979), dan teori semiotika yang dikemukakan oleh Danesi (2010) dan McCloud(2008).Berdasarkan hasil penelitian, terdapat dua bentuk pola asuh yang diterapkan tokoh ibu terhadap anak tunarungu. Kedua bentuk pola asuh tersebut yaitu, pola asuh otoriter dan pola asuh overprotektif. Faktor penyebab pola asuh ibu dibagi menjadi dua yaitu faktor internal dan faktor eksternal.Faktor internal yaitu faktor berasal dari lingkungan keluarga yang tidak dapat menerima kehadiran anak tunarungu, sedangkan faktor eksternal merupakan faktor yang berasal dari lingkungan sekolah, yaitu terdapat diskriminasi yang dialami oleh anak tunarungu. Selain itu ditemukan dua dampak negatif yang ditimbulkan akibat pola asuh otoriter dan overprotektif, yakni kepribadian anak menjadi lemah dan melarikan diri dari kenyataan.
\end{abstract}

Kata kunci : pola asuh, tunarungu, sosiologi sastra

\section{Abstract}

This research title is "Foster Parenting Against Deaf Children in Manga Koe No Katachi by Ooima Yoshitoki". This research aims to identify the types of parenting, factors, and impact that the figure of mothers bring out to the deaf kids. This research used descriptive method of analysis according to Ratna (2014). The theory used in this research were sociology of literature proposed by Wellek and Warren (in Damono, 1979), semiotics theory proposed by Danesi (2010) and McCloud (2008). Based on the results of the research, there are two forms of parenting that applied to the mother figure of a deaf child. Both forms of parenting are authoritarian parenting and overprotective parenting. Factors that cause mother's parenting are divided into two factors, internal factors and external factors. Internal factors are factors derived from the family environment that can not accept the presence of children with hearing impairment, while the external factor is a factor derived from the school environment namely, there is discrimination experienced by children with hearing impairment. In adition, two negative impacts caused by the pattern of authoritarian and overprotective, personality children to be weak and escape from reality were found.

Keywords : parenting, deaf, sociology of literature 


\section{(1) Latar Belakang}

Orang tua yang memiliki anak yang mengalami kecacatan harus berusaha untuk menghadapi segala sesuatu yang terjadi pada anaknya dengan lapang dada. Tidak jarang anak yang mengalami kecacatan mendapat perlakuan yang tidak adil dan tidak seimbang karena perbedaan yang ia miliki. Oleh karena itu peran keluarga sangat penting dalam perkembangan seorang anak yang mengalami cacat. Terutama peran ibu, seorang ibu harus berjuang dalam membesarkan anaknya yang mengalami cacat (Safaria, 2005: 5053). Perjuangan kaum ibu yang melindungi anaknya dari diskriminasi lingkungan juga banyak dicerminkan pada tokoh dalam karya sastra. Salah satu diantaranya karya sastra Jepang dalam bentuk manga yang dikarang oleh Ooima Yoshitoki berjudul Koe No Katachi. Pada manga ini terdapat pola asuh yang diterapkan tokoh ibu kepada anak tunarungu, faktor penyebab, serta dampak yang ditimbulkan dari pola asuh ibu pada anak tunarungu.

\section{(2) Pokok Permasalahan}

Berdasarkan latar belakang yang telah di jelaskan sebelumnya, maka dibuatlah rumusan masalah dalam penelitian ini sebagai berikut :

1. Bagaimanakah pola asuh ibu terhadap anak tunarungu yang tercermin dalam manga Koe No Katachi karya Ooima Yoshitoki ?

2. Bagaimanakah faktor penyebab pola asuh terhadap anak tunarungu yang tercermin dalam manga Koe No Katachi karya Ooima Yoshitoki?

3. Bagaimanakah dampak pola asuh ibu terhadap anak tunarungu yang tercermin dalam manga Koe No Katachi karya Ooima Yoshitoki ?

\section{(3) Tujuan Penelitian}

Tujuan yang ingin dicapai dalam menganalisis manga Koe No Katachi karya Ooima Yoshitoki adalah untuk mengetahui pola asuh ibu, faktor penyebab, serta dampak yang ditimbulkan dari pola asuh ibu terhadap anak tunarungu.

\section{(4)}

\section{Metode Penelitian}

Penelitian dilakukan secara kualitatif dengan metode deskriptif analisis (Ratna, 2014). Teori yang digunakan adalah Sosiologi Sastra menurut Wellek dan Warren (dalam Damono, 1979). Menggunakan konsep pola asuh untuk membantu menganalisis pola asuh, faktor penyebab, dan dampak dari pola asuh ibu terhadap anak tunarungu, serta didukung oleh teori Semiotika yang digunakan untuk menganalisis gambar pada manga.

\section{(5) Hasil dan Pembahasan}

\section{1 Pola Asuh Otoriter}

Pola asuh otoriter ialah suatu pola asuh yang cenderung membatasi, bertindak semena-mena, memaksa anak untuk mengikuti perintah-perintah orang tua dan menghormati orang tua (Hurlock dalam Thoha,1996: 111-112). Dalam manga Koe No Katachi pola asuh otoriter yang diterapkan ibu pada anak tunarungu yang bernama Nishimiya yaitu ibu memaksakan kehendaknya, dan sering bertindak semena-mena terhadap anak. Berikut penjelasan mengenai data pola asuh otoriter.

\subsubsection{Memaksa Anak Untuk Berperilaku Seperti Keinginan Orang Tua}

Dalam manga Koe No Katachi ibu memaksakan kehendaknya yaitu memotong rambut Nishimiya agar mirip seperti anak laki-laki. Berikut data yang 
menunjukan tokoh ibu memaksakan kehendaknya kepada Nishimiya.

(1) Ishida Miyako : Donna kamigata ni surutte?okaasan desune, konna kanji no desuyo niau to omoimasu

\section{Ibu}

: Damene,watashi wa korega iiwa

Ishida Miyako : Kore kurai kiruno, otokonoko mitainishite, e...

$I b u$ : Watashiwane, kono ko niwamotto tsuyoku natte hoshiinoyo otokonoko mitaini, jya basattoyacchatte

(Koe No Katachi volume 1, 2013:60-61)

Terjemahan

Ishida Miyako : Gaya rambut

seperti apa yang
kamu inginkan?
anda ibunya kan.
Saya pikir itu
akan cocok seperti
ini..
: Tidak, saya ingin
yang seperti ini
Ibu $\quad$ Memotong
Ishida Miyako
sebanyak ini,
seperti anak laki-
laki ? e...
: Saya ingin anak
saya menjadi lebih
kbu $\quad$ kuat seperti anak
laki-laki,
lakukanlah dengan
baik.

Data (1) merupakan percakapan antara tokoh ibu dengan seorang pemilik salon yang bernama Ishida Miyako. Ketika Ishida Miyako bermaksud memberi saran model potong rambut yang cocok untuk
Nishimiya, namun Ibu justru meminta model rambut seperti anak laki-laki. Dalam percakapan pada data (1) tokoh Ibu menginginkan agar rambut anaknya dipotong seperti model rambut anak lakilaki. Dapat dianalisis pada data (1) bahwa tokoh ibu menerapkan jenis pola asuh otoriter. Seperti yang telah dijelaskan sebelumnya pola asuh otoriter adalah jenis pola asuh orang tua yang memaksakan kehendaknya pada anak tanpa memberikan penjelasan. Hal itu juga diterapkan oleh tokoh ibu, dalam hal ini secara tidak langsung ia memaksa anaknya berpenampilan seperti anak laki-laki dengan mengubah model rambutnya.

\subsubsection{Orang Tua Bertindak Semena- mena}

Perilaku otoriter juga ditunjukkan oleh ibu ketika melarang Nishimiya untuk menyimpan buku komunikasi Nishimiya. Tokoh ibu menunjukkan pola asuh otoriter orang tua yang bertindak semena-mena tanpa memperdulikan pendapat Nishimiya. Adapun data sebagai berikut.

(2) Okaasan : Kore, mukashi no hitsudanyou no-to? Nandekonnamono motterunoyo... sutete shimaisai!

Ibu : Apa ini, Buku komunikasimu yang dulu ? Kenapa kamu masih memilikinya ... Lebih baik dibuang!

(Koe No Katachi volume 2, 2013: 30)

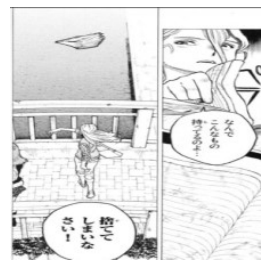

Gambar 1. Ibu membuang paksa buku 
komunikasi Nishimiya

(Koe No Katachi volume 2, 2013: 31)

Pada data (2) merupakan ungkapan ibu yang melarang Nishimiya untuk menyimpan buku komunikasinya yang dulu. Ibu melarang Nishimiya menyimpan buku komunikasi tersebut agar Nishimiya tidak mengingat masa-masa buruknya saat sekolah dasar. Setelah melarang Nishimiya untuk menyimpan buku komunikasi seperti yang diungkapkan pada data (2), ibu langsung membuang buku tersebut ke sungai seperti yang ditunjukkan pada gambar 1. Terlihat pada gambar 1 ibu Nishimiya tampak memperlihatkan ekspresi wajah marah kepada Nishimiya. Ibu langsung membuang buku komunikasi tersebut dengan melemparkannya ke sungai tanpa menanyakan pendapat Nishimiya.

Dapat dianalisis pada data (1); (2) dan gambar 1 menunjukan bahwa ibu Nishimiya menerapkan pola asuh otoriter terhadap anaknya. Seperti yang telah dijelaskan sebelumnya bahwa pola asuh otoriter adalah pola asuh yang memaksakan kehendak. Pada data (1); (2) dan gambar 1; (2) tokoh ibu memaksakan kehendaknya mengenai model rambut Nishimiya tanpa meminta pendapat Nishimiya. Tokoh ibu juga bertindak semena-mena. Saat melarang Nishimiya menyimpan buku komunikasi lama nya, bahkan ia tidak segan-segan membuang buku komunikasi anaknya.

\subsection{Pola Asuh Appeasers atau Overprotektif}

Pola asuh appeasers atau yang disebut juga overprotektif merupakan pola asuh dari orang tua yang sangat khawatir pada anaknya, bahkan seringkali ibu ikut campur dalam memilihkan teman untuk anaknya (Yusuf, $2004: 25$ ). Adapun data yang menunjukan pola asuh overprotektif tokoh ibu sebagai berikut.

\subsubsection{Orang Tua Merasa Khawatir Terhadap Anaknya}

Dalam manga Koe No Katachi tokoh ibu menunjukan kekhawatiran yang berlebihan kepada Nishimiya. Ketika Nishimiya pergi meninggalkan rumah untuk mencari adiknya yang kabur dari rumah. Ibu Nishimiya bahkan memberi peringatan yang tegas terhadap Nishimiya agar pulang tepat waktu. Adapun data sebagai berikut.

\section{(3) Okaasan : Keitai no denchi reru maeni kaerinasaitte ittadeshou, wakatteru?}

Terjemahan

Ibu : Sudah mama katakan agar pulang ke rumah sebelum ponselmu mati kan? kamu paham ?

(Koe No Katachi volume 2, 2013: 159)

Pada data (3) merupakan ungkapan ibu Nishimiya saat memarahi Nishimiya karena tidak pulang ke rumah. Pada saat itu Nishimiya mencari adiknya yang kabur dari rumah dan pada saat itu pula ponsel Nishimiya mati. Ibu Nishimiya sangat khawatir tidak dapat menghubungi Nishimiya dan segera mencari Nishimiya. Akhirnya ibu menemukan Nishimiya di jalan, ibu pun memarahi Nishimiya seperti yang diungkapkan pada data (3). Dapat dianalisis pada data (3) bahwa ibu Nishimiya menerapkan pola asuh overprotektif. Seperti yang telah dijelaskan sebelumnya pola asuh overprotektif adalah dimana orang tua merasa khawatir terhadap anaknya. Hal tersebut juga ditunjukan oleh tokoh ibu yang terdapat pada data (3). 


\subsubsection{Orang Tua Ikut Campur Dalam MemilihTeman Untuk Anaknya}

Sikap overprotektif ibu Nishimiya juga ditunjukan saat ia melarang anaknya bergaul dengan teman sekolahnya yang nakal. Adapun data sebagai berikut.

(4) Okaasan : Yuzuru, chotto. Shou chan ni kore misete agete sorede konna otoko to nakayoku shinaiyounitte tsutaete.

Terjemahan

Ibu : Yuzuru, kemari sebentar.

Tolong perlihat ini

kepada Shou chan dan

katakan padanya mama

tidak ingin dia

berhubungan dengan

laki-laki ini lagi.

(Koe No Katachi volume 2, 2013: 110)

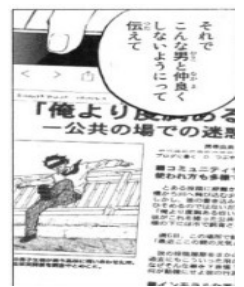

Gambar 2. Artikel Ishida melompat kesungai

(Koe No Katachi volume 2, 2013: 110)

Data (4) merupakan ungkapan yang disampaikan ibu saat ingin melarang Nishimiya bergaul dengan teman sekolahnya. Ungkapan tersebut disampaikan ibu kepada adik Nishimiya agar diterjemahkan kedalam bahasa isyarat karena ibu Nishimiya tidak bisa berbahasa isyarat. Pada data (4) menunjukan bahwa ibu Nishimiya memilihkan teman untuk Nishimiya, terlihat ibu Nishimiya melarang Nishimiya bergaul dengan orang yang tidak disukai oleh ibunya. Diceritakan bahwa ibu Nishimiya menemukan sebuah artikel yang memuat tentang temannya yang bermasalah di sekolah. Artikel yang memuat tentang teman Nishimiya yang bermasalah di sekolah ditunjukan pada gambar 2. Setelah membaca artikel tersebut ibu Nishimiya melarangnya untuk tidak bergaul dengan teman sekolahnya tersebut. Hal tersebut disampaikan ibunya kepada adik Nishimiya melalui ungkapan pada data (4).

\subsection{Faktor Penyebab Pola Asuh Terhadap Anak Tunarungu}

Faktor-faktor yang menyebabkan pola asuh orang tua yaitu adanya hal-hal yang bersifat internal dan bersifat eksternal. Faktor internal adalah lingkungan keluarga sedangkan faktor eksternal adalah lingkungan sosial dan lingkungan kerja orang tua (Soekanto, 2004:43). Berikut ini akan dijelaskan faktor penyebab pola asuh terhadap anak tunarungu.

\subsubsection{Faktor Internal}

Pada manga Koe No Katachi tokoh Nishimiya Shouko tidak diterima oleh pihak keluarganya karena ia seorang tunarungu. Berikut akan dijelaskan data yang menyebabkan faktor internal dari lingkungan keluarga.

\subsubsection{Terdapat Pihak Keluarga Yang Tidak Dapat Menerima Kehadiran Anak Tunarungu \\ Pihak keluarga yang tidak} menerima ditunjukan pihak keluarga dari ayah tokoh Nishimiya yang menganggap bahwa anak tunarungu adalah anak yang lemah dan merugikan. Adapun data sebagai berikut.
(5) Sofu
: Warui kotodato omowanainara kimi ga sodatereba iijanaika, washirano ie ni a-yu-no hairan
kakek :Jika kamu tidak berpikir itu salah, kenapa tidak kamu 
saja yang

membesarkannya?, kami

tidak ingin ada anak

seperti itu di dalam

keluarga kami.

(Koe No Katachi volume 4, 2013:71)

Data (5) merupakan ungkapan yang disampaikan oleh kakek Nishimiya kepada ibunya pada saat pertemuan keluarga. Pada data (5) kakek Nishimiya menunjukan sikap tidak menerima kekurangan yang dimilikinya dengan memberi tanggung jawab kepada ibu Nishimiya untuk merawatnya sendiri. Semua keluarga dari pihak ayah Nishimiya menganggap bahwa keadaan yang dialami Nishimiya karena dianggap mempermalukan keluarga. Keluarga dari pihak ayah tidak ingin mempunyai keturunan yang cacat seperti Nishimiya dan memberi tanggung jawab penuh kepada ibu Nishimiya untuk merawat Nishimiya sendiri.

Dapat dianalisis pada data (5) menunjukkan bahwa pihak keluarga dari ayah Nishimiya tidak menerima keberadaan Nishimiya di dalam keluarga mereka. Salah satu faktor yang membentuk pola asuh orang tua adalah dari lingkungan internal yaitu keluarga. Sehingga dapat ditarik kesamaan bahwa salah satu faktor yang membentuk pola asuh ibu Nishimiya adalah dari lingkungan keluarganya sendiri. Nishimiya tidak diterima oleh keluarga dari pihak ayahnya karena ia seorang tunarungu. Hal tersebutlah yang menyebabkan ibu Nishimiya diceraikan secara sepihak.

\subsubsection{Faktor Eksternal}

Berikut akan dijelaskan data yang menyebabkan faktor eksternal dari lingkungan sosial yaitu lingkungan sekolah Nishimiya.

\subsubsection{Terdapat Diskriminasi di Lingkungan Sekolah yang Dialami Oleh Anak Tunarungu \\ Di lingkungan sekolahnya tokoh} Nishimiya Shouko juga tidak diterima oleh teman-temannya bahkan mendapat tindakan diskriminasi. Diskriminasi yang di terima Nishimiya salah satunya merusak alat bantu dengar Nishimiya. Adapun data sebagai berikut.

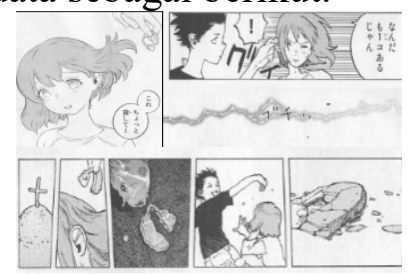

Gambar 3. Teman merusak alat bantu dengar Nishimiya

(Koe No Katachi volume 1, 2013:105-106)

Gambar 3 menunjukan diskriminasi yang dilakukan oleh teman Nishimiya di sekolah. Salah satu teman sekelas Nishimiya yaitu Ishida yang merusak alat bantu dengar Nishimiya. Pada saat itu Nishimiya sedang duduk di kelasnya, kemudian Ishida merampas alat bantu dengar Nishimiya secara paksa dan melemparnya sehingga pecah. Karena diambilnya secara paksa sehingga telingga Nishimiya mengeluarkan darah. Dapat dianalisis pada gambar 3 Nishimiya mendapat diskriminasi dari temantemannya di sekolah dengan cara merusak alat bantu dengar milik Nishimiya.

Dapat dianalisis diskriminasi yang dilakukan teman-teman Nishimiya di sekolah yaitu dalam bentuk kekerasan. Faktor eksternal yang membentuk pola asuh orang tua yaitu lingkungan di luar rumah salah satunya lingkungan sekolah. Terbentuknya pola asuh overprotekif dan otoriter yang ditunjukan oleh tokoh ibu terhadap Nishimiya, salah satunya dipengaruhi oleh faktor eksternal tersebut. 
Tokoh ibu sengaja menunjukan pola asuh otoriter dan overprotektif bertujuan agar anaknya Nishimiya menjadi pribadi yang kuat dalam menghadapi berbagai diskriminasi yang dialami baik dari lingkungan keluarga maupun di lingkungan sosialnya.

\subsection{Dampak Pola Asuh Ibu Terhadap Anak Tunarungu}

Hurlock (dalam Thoha, 1996 :111) menjelaskan bahwa dampak dari pola asuh otoriter dan overprotektif yaitu diantaranya kepribadian anak menjadi lemah dan tidak berani menghadapi masalah, hal tersebut juga dialami oleh tokoh Nishimiya yang diakibatkan dari pola asuh otoriter dan overprotektif yang diterapkan oleh ibunya. Adapun penjelasan dampak dari pola asuh otoriter dan overprotektif sebagai berikut.

\subsubsection{Kepribadian Anak Menjadi Lemah}

Akibat dari pola asuh ibunya yang overprotektif dan otoriter Nishimiya tumbuh menjadi anak dengan memiliki kepribadian yang lemah. Ketika didiskriminasi oleh teman-temannya di sekolah Nishimiya tidak berani membela dirinya. Adapun berikut data dalam bentuk gambar yang menunjukkan Nishimiya memiliki kepribadian yang lemah.

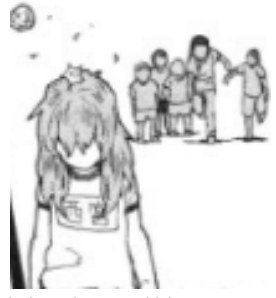

Gambar 4. Nishimiya dilempari batu oleh teman-temannya

(Koe No Katachi volume 2, 2013: 116)

Gambar 4 merupakan gambaran Nishimiya yang sedang didiskriminasi oleh temannya tanpa melakukan perlawanan sedikitpun. Pada saat itu sedang dalam perjalanan pulang dari sekolah. Melihat Nishimiya berjalan sendirian temantemannya memanfaatkan situasi tersebut untuk mendiskriminasi Nishimiya. Mendapat perlakuan yang tidak baik dari temannya Nishimiya hanya diam saja dan tidak mau membela dirinya. Hal tersebutlah yang menunjukan bahwa Nishimiya memiliki kepribadian lemah, dikarenakan ia bahkan tidak bisa membela dirinya sendiri.

Dapat dianalisis pada gambar 4 menunjukkan bahwa Nishimiya memiliki kepribadian yang lemah yang diakibatkan dari pola asuh otoriter dan overprotektif dari ibunya. Pada gambar 4 kepribadian lemah dari tokoh Nishimiya ditunjukkan saat ia tidak membela dirinya ketika didiskriminasi oleh teman sekolahnya.

\section{(6) Simpulan}

Berdasarkan hasil penelitian dapat disimpulkan tokoh ibu menerapkan dua pola asuh yaitu pola asuh otoriter dan pola asuh overprotektif. Pada penelitian ini tokoh ibu menerapkan pola asuh otoriter dengan memaksa anak untuk berperilaku seperti keinginan orang tua dan orang tua bertindak semena-mena sedangkan pola asuh overprotektif ditunjukkan oleh tokoh ibu dengan merasa khawatir berlebihan terhadap anaknya, dan ikut campur dalam memilih teman untuk anaknya serta orang tua terlalu melindungi anaknya. Terdapat dua faktor penyebab yaitu pertama, faktor internal yang mempengaruhi pola asuh ibu yaitu terdapat pihak keluarga yang tidak dapat menerima kehadiran anak tunarungu. Kedua, faktor eksternal yang mempengaruhi yaitu terdapat diskriminasi di lingkungan sekolah yang dialami oleh anak tunarungu. Dampak yang timbulkan dari pola asuh otoriter dan overprotektif yang diterapkapkan tokoh ibu terhadap 
Nishimiya yaitu dibagi menjadi dua yaitu pertama, kepribadian anak menjadi lemah, kedua, tidak berani menghadapi masalah.

\section{(6) Daftar Pustaka}

Damono, Sapardi Djoko. 1979. "Sosiologi Sastra Sebuah PengantarRingkas". Jakarta : Pusat Pembinaan dan Pengembangan Bahasa Departemen Pendidikan dan Kebudayaan.

Danesi, Marcel. 2010. "Pesan, Teks, Tanda, dan Makna: Buku Teks Dasar Mengenai Semiotika dan Teori Komunikasi”. Yokyakarta: Jalasutra.

McCloud, Scott. 2008. "Understanding Comic (Memahami Komik)". Jakarta: Kepustakaan Populer Gramedia.

Ratna, Nyoman Kutha. 2014. "Teori, Metode, dan Teknik Penelitian Sastra". Yogyakarta: Pustaka Pelajar.

Safaria, T. 2005. Autisme:"Pemahaman Baru Untuk Hidup Bermakna Bagi Orang tua". Yogyakarta: Graha ilmu.

Soekanto, Soejono. 2004. Sosiologi Suatu Pengantar. Jakarta: PT Raja Grafindo Persada.

Thoha, C. 1996. Kapita Selekta Pendidikan Islam, Yogyakarta: Pustaka Pelajar (IKAPI)

Yusuf, Syamsu. 2004. Psikologi Perkembangan Anak dan Remaja. Bandung : PT Remaja Risdakarya Offset. 